\title{
LOS RETOS DE LA DEMOCRACIA: LA DEMOCRACIA PARTICIPATIVA COMO COMPLEMENTO DE LA DEMOCRACIA REPRESENTATIVA
}

\author{
Alfredo Ramírez Nárdiz \\ Profesor doctor de Derecho constitucional \\ Universidad Católica San Antonio de Murcia
}

\begin{abstract}
Sumario. 1. Introducción. 2. Orígenes históricos. 3. La democracia participativa. 4. Diferenciación terminológica y conceptual. 5. Democracia participativa y democracia representativa. 6. Instrumentos de la democracia participativa. 7. Estado de la democracia participativa en los distintos ámbitos territoriales: la importancia del ámbito local. 8. Conclusiones.
\end{abstract}

\section{INTRODUCCIÓN.}

En la actualidad la Democracia Participativa es uno de los más destacados campos de desarrollo del Derecho, la política y la administración. Uno de los ámbitos en los que la Democracia en mayor medida demuestra que es un sistema político vivo, que se desarrolla y que se transforma, que está en continuo cambio y que, ni mucho menos, ni en la teoría ni en la práctica, se encuentra definitivamente terminado o amortizado. Sin embargo, debido precisamente a su carácter actual y esencialmente moderno, la Democracia Participativa es también una de las áreas más desconocidas del todo que es la Democracia. Su cada vez mayor práctica por parte de las administraciones públicas, especialmente en el ámbito local o municipal, no la ha hecho más y mejor conocida, al contrario, en no pocos casos ha generado confusión y dudas sobre qué es y como utilizarla. Son muchos, cada vez más, los artículos, seminarios y actividades, tanto prácticas como teóricas, que se realizan para estudiar qué es la Democracia Participativa, en qué consiste, cómo se desarrolla, cuáles son sus consecuencias y, lo más importante, cuál es su futuro, a dónde nos lleva a los ciudadanos que, nos guste o no, seamos siquiera conscientes de su existencia o no, nos vemos envueltos cada día en mayor medida en ella y en los instrumentos y mecanismos jurídicos en los que se materializa. En las presentes líneas se pretende realizar un acercamiento a la Democracia Participativa. Esto es, al conjunto de elementos que componen tanto la presente teoría jurídica como la práctica política de la Democracia Participativa. Conocer su origen histórico, su aparición en nuestros tiempos, su situación actual, sus relaciones con la Democracia Representativa, diferenciarla de otros conceptos con los que habitualmente se la relaciona, exponer los instrumentos jurídicos que esencialmente la componen y hacer una breve referencia a su más probable desarrollo futuro. Las páginas siguientes 
han de ser entendidas, por tanto, como una introducción general al concepto de la Democracia Participativa.

\section{ORÍGENES HISTÓRICOS.}

Si la Democracia Participativa ha de tener un origen histórico remoto, éste se encuentra en la Democracia Directa ateniense. Es en la Grecia clásica $\mathrm{y}$, en particular, en la ciudad de Atenas en los tiempos de Pericles, cuando surge la idea del gobierno de los ciudadanos por los propios ciudadanos. ${ }^{1}$ Comunidad política reunida en la Asamblea, que decidía sobre las diversas cuestiones que componían la vida de la ciudad y que tomaba las decisiones mediante el sistema de voto individual y triunfo de la mayoría. El modelo ateniense no era, sin embargo, una Democracia Directa tan pura como se tiende a pensar. Esto es, no había una relación plenamente directa entre el voto del ciudadano en la Asamblea y la decisión política final sin ningún tipo de intermediario, ni representante. Muy al contrario, aunque sí es cierto que la decisión final la tomaba el conjunto de la comunidad reunida en la Asamblea, hasta llegar al momento de tomar dicha decisión entraban en juego no pocos órganos intermedios de carácter representativo que trataban de racionalizar el proceso de toma de decisiones políticas y permitir en la práctica el gobierno directo que la Asamblea ejercía. ${ }^{2}$ La Democracia Directa ateniense, aun e introducir un elemento esencialmente novedoso y que por necesidad goza de una importante carga positiva desde la perspectiva actual como es la toma de decisiones mediante el voto igualitario de los ciudadanos, se caracterizaba por una serie de elementos que no la hacen homologable, ni siquiera deseable, en el presente, destacando entre ellos el hecho de que los únicos que podían votar eran los ciudadanos atenienses libres de sexo masculino. Esto es, estaban excluidos del derecho de sufragio tanto las mujeres, como los esclavos, como los extranjeros o metecos (entre

${ }^{1}$ Aristóteles comenta que «en tiempos de Pericles el estado se hizo más democrático aun (...) así, el pueblo se atrevió a intervenir por sí mismo en todos los ámbitos de gobierno (...)» Aristóteles, Constitución de los atenienses, 27, 1, en DAvies, J. K. La democracia y la Grecia Clásica, Taurus, Madrid, 1981, p. 58.

${ }^{2}$ Por citar algunos de estos órganos intermedios que racionalizaban el proceso decisorio quepa citar al Consejo o Senado llamado Bulé y cuya función era estudiar los proyectos de ley de forma anticipada emitiendo un informe que presentaba a la Asamblea; o los arcontes temotestas, que controlaban la legislación, intervenían de forma preventiva en la función legislativa, revisaban las leyes y determinaban si existía algún tipo de contradicción entre ellas y, en la información preliminar del procedimiento, hacían referencia a las posibles innovaciones inútiles o peligrosas y proponían supresiones, adiciones y enmiendas pudiendo llegar a paralizar un proyecto de ley. Ramírez Nárdiz, A. Democracia Participativa. La Democracia Participativa como profundización en la Democracia, Tirant lo Blanch, Valencia, 2010, pp. 25-27. 
los cuales, paradójicamente, se encontraban la mayoría de los sofistas, es decir, de los maestros de la clase dirigente ateniense). ${ }^{3}$

En la práctica, la Asamblea ateniense estaba formada por no más de 5.000 hombres libres que decidían por el conjunto de la comunidad sin tener en cuenta ni a las mujeres, ni a los esclavos. De hecho, era en gran medida la existencia de la esclavitud la que permitía la Democracia Directa al liberar de cargas laborales a los ciudadanos atenienses y, gracias a ello, darles tiempo que dedicar a actividades como la filosofía y la política. Esta paradoja entre una sociedad que introducía uno de los elementos básicos que componen el actual concepto de la Democracia, cual era la toma de decisiones mediante el sistema de mayorías surgidas del voto individual de los ciudadanos, pero que negaba el derecho de igualdad y que, en general, priorizaba la voluntad de la Asamblea sobre cualquier otra variable como la de los derechos individuales de los propios ciudadanos (como muestra el famoso ejemplo del juicio y condena de Sócrates) ha llevado a no pocos autores a posicionarse como ya hiciera en el siglo XIX Constant, quien diferenciara entre la "libertad de los antiguos" y la "libertad de los modernos" (donde la de los antiguos implica el poder máximo de las decisiones de la mayoría sobre cualquier otro elemento y la de los modernos -es decir, la que comienza con las revoluciones liberales de los siglos XVII y XVIII- somete dicho poder de la mayoría a una serie de elementos -derechos individuales, división de poderes, Estado de Derecho, etc.- que ejercen de contrapeso y limitan la decisión de la mayoría) eligiendo claramente la de los modernos y no deseando de ninguna de las maneras la de los antiguos. ${ }^{4}$

El modelo de Democracia Directa ateniense encuentra su sucesor histórico en la Roma republicana y en las instituciones de los comicios y los plebiscitos. ${ }^{5}$ El modelo romano no es ya, sin embargo, como el ateniense y la participación directa de los ciudadanos en la toma de las decisiones es mucho más reducida y limitada. Además, la República Romana, momento histórico en el que se desarrollarían las prácticas participativas, evolucionaría hacia el Imperio y con él la participación ciudadana se iría reduciendo progresivamente hasta resultar meramente anecdótica. Si el periodo histórico romano es de destacar es porque en él aparece el que con el paso de los siglos habría de ser el otro gran pilar de la Democracia tal y como se

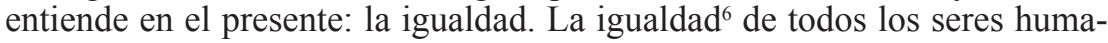

3 VIDAL-NAQUET, P. La democracia griega, una nueva visión, Akal Universitaria, Madrid, 1992, pp. 46-56.

${ }^{4}$ Constant, B. «De la libertad de los Antiguos comparada con la de los Modernos», Escritos políticos, Centro de Estudios Constitucionales, Madrid, 1989, pp. 257-285.

${ }^{5}$ Daza Martínez, J. Iniciación al estudio histórico del Derecho romano, Universidad Complutense, Madrid, 1997, pp. 83-86.

${ }^{6}$ Como indica Manin, «la concepción moderna del Derecho Natural se basa en la idea de que todos los seres humanos comparten un elemento esencial de igualdad, ya se 
nos con independencia de sus circunstancias personales surge dentro del pensamiento cristiano, el cual aparece en tiempos del Imperio Romano y se extiende por todo el territorio del Imperio hasta acabar convirtiéndose en la religión oficial del mismo. ${ }^{7}$

La participación ciudadana directa, junto con todo el pensamiento político greco-romano, pasa a un estado de latencia conforme avanza el Imperio y durante la Alta Edad Media para apenas mostrar algunos ejemplos puntuales de desarrollo y práctica en la Baja Edad Media (caso de algunas ciudades-estado italianas) y volver progresivamente a la actualidad teórica a lo largo del Renacimiento y, especialmente, del Barroco. En el siglo XVII aparecen tanto pensadores políticos como movimientos sociales (ejemplo de los cuales son los levellers - niveladores- y diggers -cavadores- en Inglaterra) que retoman la idea de la moderación del poder absoluto del monarca y teorizan sobre los modelos políticos más adecuados, así como sobre la necesaria protección de las libertades y derechos de los individuos frente al poder del Estado. Esta evolución teórica daría lugar a la revolución liberal inglesa de finales del siglo XVII y continuaría y se potenciaría a lo largo del siglo XVIII con los ilustrados franceses y con la figura peculiar y personal de Rousseau, quien (como buen heredero de la tradición participativa local de su Suiza natal) sería el autor que con más fuerza y decisión abogaría por el gobierno directo de los ciudadanos que, como titulares de la soberanía, serían los llamados a ejercerla personalmente ${ }^{8}$, reunidos en asamblea y sin necesidad de representantes ${ }^{9}$. El pensamiento ilustrado cristaliza en las re-

denomine voluntad, razón o conciencia.» MANIN, B. Los principios del gobierno representativo, traducción de Fernando Vallespín, Alianza, Madrid, 1998, p. 194.

7 SChumpeter comenta que «(...) tomemos la igualdad. Su significado preciso permanece dudoso y apenas hay justificación racional para exaltarla como postulado en tanto que nos movemos en la esfera del análisis empírico. Pero la Cristiandad alberga un fuerte elemento igualitario. El Redentor murió por todos; Él no hizo diferencias entre los individuos de los distintos status sociales. Al obrar así atestiguó el valor intrínseco del alma individual, un valor que no admite gradaciones. ¿No es esto una sanción -y, a mi parecer, la única sanción posible- de la fórmula cada uno cuenta como uno, nadie cuenta como más de uno (...)?» Schumpeter, J. A. Capitalismo, socialismo y democracia, Aguilar, Madrid, 1971, pp. 339-340.

8 «Digo pues, que, no siendo la soberanía otra cosa que el ejercicio de la voluntad general, no puede ser enajenada, y que el Soberano, ser colectivo y nada más, sólo puede ser representado por sí mismo.» Rousseau, J. J. El contrato social, libro II, cap I, Alba, Madrid, 1996, pp. 43-44.

${ }^{9}$ La crítica al pensamiento rousseauniano es bien conocida y radica en la necesaria diferenciación entre poder constituyente y poder constituido de la que carece el modelo del ginebrino. Como indica Aragón Reyes «el Estado constitucional (...) optó (...) por la democracia representativa. Y esta opción no se basaba principalmente en razones utilitarias o, si se quiere, de eficacia (...) sino, sobre todo, en razones de coherencia teórica con el tipo de forma política que se adoptaba, basada en una Constitución que garantizase que 
voluciones liberales de los EEUU primero y de Francia posteriormente y se extiende por toda Europa y América a lo largo del siglo XIX. A su vez, el pensamiento de Rousseau se convierte en punto de partida y substrato desde el cual los sucesivos movimientos demócratas primero y socialistas, comunistas y anarquistas después se inspirarán durante la segunda mitad del siglo XIX en sus demandas de mayores derechos sociales, de sufragio universal o, incluso, de cambio de modelo desde el Estado liberal al Estado socialista.

El final del siglo XIX y el principio del siglo XX vive el conflicto entre las ideas liberales desarrolladas e implantadas durante el XIX y las ideas demócratas y socialistas que con gran fuerza se habían manifestado en momentos puntuales (Comuna de París en 1870) pero que en ningún momento llegaron a alcanzar el poder de una manera continuada. Terminada la Primera Guerra Mundial, y ante el advenimiento de la Unión Soviética como modelo político-económico alternativo, surge en Europa una nueva generación de constituciones que, a modo de intento de establecer un punto de encuentro entre las distintas sensibilidades sociales, constitucionalizan los derechos sociales y recogen toda una serie de instrumentos de participación directa de los ciudadanos en la vida política y en la toma de decisiones, tales como el referendo o la iniciativa popular. Este conjunto de constituciones, entre las cuales aparece la española de 1931, tuvo como más destacado ejemplo la Constitución alemana de Weimar de 1919. Este periodo de entreguerras y la regulación jurídica que entonces se hizo de la participación directa es el antecedente histórico inmediato de la actual Democracia Participativa. ${ }^{10}$

\section{LA DEMOCRACIA PARTICIPATIVA.}

En los años sesenta y primeros setenta del siglo XX se produce una evolución generalizada de la sociedad occidental. Diversos movimientos políti-

la soberanía perteneciese a la nación y, por lo mismo, que el poder político institucionalizado en el Estado había de ser limitado y nunca absoluto. Ello exigía la distinción entre poder constituyente y poder constituido, lo que se hacía imposible si los dos estuviesen materialmente confundidos. De ahí el fracaso de la democracia rousseauniana que basaba todo el ejercicio del poder en una sola fuente: la voluntad popular, única instancia capaz de expresar la voluntad general.» Aragón ReYes, M. «Democracia y Parlamento», Revista Catalana de Dret Públic, no 37, Generalitat de Catalunya, Escola d'administració pública de Catalunya, 2008, p. 130.

${ }_{10}$ Jurista esencial de este periodo y de toda la teoría constitucional del mismo es KELSEN, el cual concebía los instrumentos participativos como un mecanismo para fortalecer la Democracia Representativa y el parlamentarismo. Este fortalecimiento, en una época turbulenta en la que los radicalismos de uno y otro extremo eran cada vez más fuertes, era el verdadero objetivo de toda reforma política y, entre ellas, de la introducción en los textos constitucionales de mecanismos jurídicos que permitían la intervención directa del ciudadano en la vida política. Intervención que debía entenderse como una forma de hacer a dicho ciudadano comprometerse más intensamente con la democracia. En esta dirección señala IGNACIO DE OTTO cuando sobre KELSEN afirma que «aunque KELSEN pro- 
cos, religiosos y sociales se superponen con la voluntad de cambiar el estado de cosas anterior y dotar a la sociedad de una nueva configuración en la que el número y profundidad de los derechos de los ciudadanos aumente y se desarrolle. Estas peticiones de cambio proceden de un número tan diverso y plural de ámbitos que se puede hablar de un deseo generalizado de cambio. Ya sea desde la esfera política (descolonización, derechos sociales, derechos civiles para minorías raciales y étnicas, reformulación de la izquierda), como desde la religiosa (Concilio Vaticano II), como desde la social (movimientos feministas, pacifistas, hippies), como desde la económica (sociedad postindustrial), el número de voces reclamando cambios y una nueva perspectiva y concepción de la sociedad son multitud. ${ }^{11}$ Es dentro de este caldo de cultivo y como parte integrante del mismo donde aparece la Democracia Participativa. ${ }^{12}$

La petición de mayores cuotas de participación de los ciudadanos en la vida pública, especialmente de participación directa, no surge súbitamente y por primera vez en un lugar concreto. Como ya se ha indicado, el diálogo participación-representación es constante desde hace siglos (baste, por ejemplo, recurrir a las opiniones de CONDORCET o SIEYĖs para comprobar que en

pugna sistemas de democracia directa, como el referéndum, cuyas posibilidades de uso plebiscitario-autoritario no estaban aun tan claras como hoy, sus propuestas se dirigen a una mayor vinculación del Parlamento con el elector, lo que no es posible sin una activación de éste y, por tanto, sin una prolongación de su actividad política más allá de la acción de depositar su voto en una urna.» OTto, I. DE, en KeLSEN, H. Esencia y valor de la democracia, Guadarrama, Colección Punto Omega, Madrid, 1977.

${ }^{11}$ Desde una perspectiva algo más prosaica y bastante más negativa siempre se podría afirmar que el surgimiento de este amalgama de movimientos sociales se encuentra directamente relacionado con el asentamiento más y más fuerte del modelo económico capitalista. Es decir, las peticiones de mayores y más profundos derechos ciudadanos que comienza en los años sesenta y que, en no pocos ámbitos, continúa en la actualidad, no sería más, desde la perspectiva citada, que un conjunto de reclamaciones periféricas que se producen una vez el pilar fundamental de la sociedad -el modelo económico- se da por descontado y no existe ninguna alternativa real al mismo más allá de su propia evolución interna. Dado que el sistema de economía de mercado, eje esencial de la sociedad que determina los intercambios de riqueza y el bienestar material de los ciudadanos, es firme e inamovible, a las "fuerzas del cambio" no les quedaría más remedio que refugiarse en ámbitos "menores" de la convivencia social tales como, por ejemplo, los derechos de las minorías o la concepción de las relaciones familiares. Desde esta perspectiva, todas estas reclamaciones de cambio, sin dejar de ser importantes, no serían más que la prueba palpable de que la sociedad parece dirigirse con firmeza hacia un modelo social y económico único caracterizado por la Democracia Representativa y el modelo productivo capitalista que sólo admite cambios y reformulaciones en su periferia pero nunca en su núcleo esencial.

12 Aguiar de Luque, L. y Sánchez Morón, M. en Alzaga Villaamil, Ó. «Comentarios a las Leyes Políticas. Constitución Española de 1978», Revista de Derecho Privado, Editoriales de Derecho Reunidas, Madrid, 1985, tomo II, pp. 657-658. 
los debates de la Revolución Francesa fue un tema recurrente y polémico $\left.{ }^{13}\right)$. La utilización de mecanismos de participación directa de los ciudadanos en las decisiones políticas se produce en no pocas ocasiones desde finales del siglo XVIII y a lo largo de todo el siglo XIX (casi siempre más como recurso plebiscitario y populista que como verdadera mejora democrática) y la constitucionalización de instrumentos de participación directa es ya algo habitual desde el primer tercio del siglo XX. No obstante, por fijar un punto de partida formal y convencional de la actual doctrina de la Democracia Participativa, cabría citar la Alemania de los últimos años sesenta y primeros setenta del siglo XX. En este marco aparecen teóricos como HABERMAS ${ }^{14} \mathrm{o}$ DiENEL, se produce jurisprudencia regional solicitando mayores niveles de participación de los ciudadanos en la toma de las decisiones políticas ${ }^{15}$, se idean nuevos mecanismos de participación directa y, progresivamente y debido al desarrollo y evolución de los instrumentos participativos, se percibe y asume que el ámbito natural de la participación directa, donde con mayor fuerza se asienta, donde muestra más innovaciones, donde es más utilizada por las administraciones y más valorada por los ciudadanos, es local. Es en el área formada por las regiones del sur de Alemania (especialmente BadenWuttemberg y Baviera), no por casualidad fronterizas con Suiza, allí donde el fenómeno se desarrolla no sólo en la práctica sino también en la teoría y donde toma cuerpo la idea de que la participación ciudadana directa, si bien puede tener cierta relevancia en los ámbitos nacional y regional, donde más

${ }^{13}$ El pensamiento de Condorcet y su evolución a lo largo de los años es en sí mismo ejemplo de dicho diálogo participación-representación. CONDORCET parte de defender postulados propios del modelo británico de Democracia Representativa censitaria en tiempos previos a la Revolución Francesa a inclinarse por el sufragio universal y la participación directa conforme la Revolución se desarrolla, para finalmente considerar que lo más adecuado es un modelo esencialmente representativo que permita en su seno elementos de participación directa. CONDORCET, J. M. Bosquejo de un cuadro histórico de los progresos del espíritu humano, Editorial Nacional. Madrid, 1980, pp. 43-44.

${ }^{14}$ En la obra Strukturwandel der Öffentlichkeit HABERMAs plantea una vida pública decadente en la que se disuelve la substancia de la democracia liberal a causa de una combinación de manipulación plebiscitaria y apatía privada donde desaparece la colectividad de los ciudadanos. Sin embargo, HaBERMAs no lo da todo por perdido y concibe la posibilidad de una recuperación del ámbito de lo público mediante una democratización de los partidos políticos, la labor de las asociaciones voluntarias y el fortalecimiento de la sociedad civil. Habermas, J. Ensayos políticos, Ediciones península, Barcelona, 1988, pp. 211-212.

${ }^{15}$ El Tribunal Constitucional de Renania del Norte-Westfalia por sentencia de 28 de septiembre de 1973 exigió al legislador crear nuevas instituciones que ofreciesen a los ciudadanos la sensación de estar más implicados en los asuntos de la colectividad. DIENEL, P.C. y HaRms, H. Repensar la democracia. Los núcleos de intervención participativa, Ediciones del Serbal, Barcelona, 2000, p. 22. 
posibilidades tiene (a modo de interesante revisión del pasado ateniense) es en el municipio, en la ciudad. ${ }^{16}$

Con el paso de los años, la participación directa se extiende al conjunto de Europa y se desarrolla igualmente en América produciéndose un diálogo en el que ambas orillas del Atlántico toman y dan tanto aportaciones teóricas como prácticas a sus vecinos de más allá del mar. En los EEUU, la participación ciudadana directa en el ámbito de lo local, históricamente muy asentada en la tradición de este país, resurge con fuerza desde los años setenta, si bien no por los mismos motivos que en Europa, sino, por contra, como respuesta o reacción al poder del gobierno federal en la época del presidente Carter. ${ }^{17}$ En Iberoamérica el desarrollo de la participación se retrasa hasta los años ochenta, pero es justo allí donde se manifiesta con mayor fuerza y originalidad creando y potenciando mecanismos participativos que con los años se extenderán por todo el mundo. Ejemplo paradigmático de esto son los presupuestos participativos surgidos en Brasil a finales de los ochenta o todo el proceso de reformas constitucionales que apuestan por la participación directa y que tienen su pistoletazo de salida en Colombia en los primeros noventa y se prolongan en Venezuela, Bolivia o Ecuador con el final del siglo XX y el comienzo del siglo XXI.

Es en paralelo a estos cambios cuando aparece el mismo término Democracia Participativa. Es muy complicado, casi imposible, encontrar textos normativos que recojan este término. En la mayoría de las Constituciones o leyes de distinto tipo que regulan la participación directa se hace referencia a la Democracia Directa, a la Democracia Semi-directa, a la Participación Ciudadana, etc. pero no a la Democracia Participativa. El Tribunal Constitucional ha aportado la denominación "Fenómeno Participativo" para referirse a todos los mecanismos que favorecen la participación de los ciudadanos en la vida pública, incluso más allá del ámbito político, y que forman un espectro mucho mayor que el estrictamente propio de la Democracia Directa (curiosamente, Democracia Directa es la terminología usada por el Tribunal Constitucional para, en términos generales, referirse a lo que la doctrina llama actualmente Democracia Participativa). ${ }^{18}$

Lo cierto, es que el término Democracia Participativa es de creación y uso esencialmente doctrinal, es decir, académico y de investigación, pero, posiblemente debido a su novedad y a que los otros citados poseen una carga

${ }^{16}$ Ejemplo de esto son los núcleos de intervención participativa, que surgen a principios de los años setenta en Wuppertal (República Federal de Alemania). Dienel, P. C. Y Harms, H.D. op. cit., Ediciones del Serbal. Barcelona, 2000, pp. 7 y 83.

17 Finkielkraut, A. La nueva derecha norteamericana. La revancha y la utopía, Anagrama, Barcelona, 1982.

${ }_{18}$ El TC retomó la expresión Fenómeno Participativo en su STC 103/2008, de 11 de septiembre, FJ $2^{\circ}$. Esta expresión ya la había utilizado en el pasado en sentencias como la STC 119/1995, de 17 de julio, FJ 4². 
política, de uno u otro sentido, más apropiada para citarlos en la legislación, no ha tenido mucha divulgación en los textos normativos. No obstante, doctrinalmente, el término Democracia Participativa es cada vez más unánimemente aceptado como el más adecuado para referirse al conjunto de instrumentos o mecanismos jurídicos que, a través de la participación directa de los ciudadanos en el gobierno de la comunidad, pretenden profundizar en la democracia permitiendo a los ciudadanos tanto tomar parte directamente en la decisión de los asuntos que les conciernen, como aumentar el control que ejercen sobre sus representantes y gobernantes ${ }^{19}$.

La Democracia Participativa se materializa en multitud de instrumentos jurídicos que son susceptibles de ser usados para los fines señalados en el párrafo anterior o bien para justo lo contrario. De hecho, este sentido opuesto, al que podría llamarse Democracia Populista o Democracia Plebiscitaria ${ }^{20}$, es aquel en el que, en su gran mayoría, fueron utilizados los mecanismos participativos en el siglo XIX y en muchos momentos del siglo XX (como así sucedió con los referendos del Franquismo) desprestigiando en no pocos ámbitos la participación directa de los ciudadanos, fomentando corrientes de opinión que parten precisamente de las bondades de una democracia en la que la participación de los ciudadanos en los asuntos públicos sea lo más reducida posible ${ }^{21}$ y contribuyendo a que en textos constitucionales como el

${ }_{19}$ Aumentar el control, pues con carácter previo a cualquier introducción de instrumentos participativos, el ciudadano ya puede ejercer control sobre sus representantes mediante el instrumento de control por excelencia, cual es el voto en las elecciones. Tal como indica MANIN «la característica más importante de los sistemas representativos, que permite a los votantes influir en las decisiones de sus representantes, es el carácter periódico de las elecciones.» Si bien, este mismo autor ya indica que «se siente intuitivamente que las elecciones periódicas dan a los gobernados cierto control sobre la conducción de los asuntos públicos, pero no está claro por qué esto haya de ser así, dada la ausencia de mandatos imperativos y de promesas electorales vinculantes.» Manin, B. op. cit., Madrid, 1998.

20 Este término es usado por autores como Lissidin para referirse a la forma en que se usa la Democracia Participativa en la actual Venezuela de Hugo Chávez. Lissidini, A. La democracia directa en Venezuela: ¿democracia participativa o democracia plebiscitaria?, C2D, Zurich, 2008, p. 13.

${ }^{21}$ Especialmente populares y conocidas son aquí las opiniones de SCHUMPETER cuando indica que la democracia «no significa ni puede significar que el pueblo gobierna efectivamente, en ninguno de los sentidos evidentes de las expresiones pueblo y gobernar (...)» La democracia implica simplemente «que el pueblo tiene la oportunidad de aceptar o rechazar los hombres que han de gobernarle.» Siendo el otro criterio identificador del método democrático «la libre competencia entre los pretendientes al caudillaje por el voto del electorado.» En definitiva, «los electores (...) deben comprender que, una vez que han elegido a un individuo, la acción política le corresponde a él y no a los electores.» Schumpeter, J. A. op. cit., Aguilar, Madrid, 1971, pp. 362 y 374. 
español de 1978 se regulara la participación directa de los ciudadanos de una forma restrictiva y temerosa. ${ }^{22}$

La Democracia Participativa aparece en el presente como una de las más sólidas áreas de desarrollo de la Democracia, centrada cada vez más en el ámbito de lo local y compuesta de una pluralidad de instrumentos jurídicos numerosa, diversa y que aumenta conforme más administraciones deciden regularla e incorporarla a sus ordenamientos. Practicada en un número creciente de ámbitos, estudiada e investigada desde perspectivas tanto jurídicas, como políticas, como sociológicas y dotada de un valor positivo que la hace ser popular tanto en Europa, como en América como en latitudes externas a Occidente. ${ }^{23}$ La Democracia Participativa se muestra en la segunda década del siglo XXI como una de las más firmes opciones de las que se dispone en la actualidad para revitalizar la Democracia, superar la tantas veces citada crisis de la representación y tratar de profundizar y mejorar el modelo político democrático.

\section{DIFERENCIACIÓN TERMINOLÓGICA Y CONCEPTUAL.}

Como esencialmente moderno y reciente que es, el término utilizado para nombrar la Democracia Participativa no es de aceptación unánime. La legislación (tanto española como internacional) tiende a no hacer referencia a la expresión Democracia Participativa y existe una serie de términos que, aun y la casi unánime aceptación doctrinal de Democracia Participativa como el más adecuado, se usan, se confunden y se entremezclan en no pocas ocasiones. Es por ello de especial interés intentar establecer una diferenciación entre ellos.

- Democracia Participativa: es el conjunto de instrumentos jurídicos que, a través de la participación directa de los ciudadanos en la vida pública, en la toma de decisiones de la comunidad y en el control de sus representantes y gobernantes, pretende profundizar en la democracia implicando en un mayor modo al ciudadano en su propio gobierno.

${ }^{22}$ En palabras de Alzaga «nuestros constituyentes, que, de un lado, no habían olvidado los referenda franquistas, sistemáticamente enmarcados en la propaganda oficial y unidireccional en favor del sí de turno y que, de otro, deseaban consolidar el sistema de partidos políticos como principales herramientas de la democracia representativa y que, además, albergaban algún temor a las posibilidades que podían tener los grupos extremistas de derecha e izquierda a la hora de manejar mecanismos extraparlamentarios, fueron muy cautos en la instauración de dispositivos de participación popular directa.» AlzAGA VILlaAmil, Ó. Derecho político español según la Constitución de 1978, Edersa, Madrid, 1996, p. 295.

${ }^{23}$ Los ejemplos son muchos. Por citar sólo uno baste hablar de la India y de uno de sus estados, Kerala, el cual ha adquirido popularidad por el desarrollo participativo llevado a cabo en el mismo. Thomas IsAac, T.M. y Franke, R. Democracia local y desarrollo. Campaña popular de planificación descentralizada de Kerala, Diálogos L'Ullal Edicions, Játiva, 2004. 
- Democracia Semi-directa: este era el término habitualmente utilizado en la segunda mitad del siglo XX para referirse a lo que en el presente se entiende por Democracia Participativa. Es fácil encontrarlo, por ejemplo, en los debates constituyentes españoles en las intervenciones de FrAGA, que defendía una regulación más profusa de la participación directa en la Constitución y que acostumbraba a utilizar esta expresión..$^{24}$ No es, sin embargo, muy acertada, pues, evidentemente, ni lo que en los años setenta se entendía por Democracia Semi-directa, ni lo que hoy es la Democracia Participativa llegan, ni de lejos, a ser la mitad de lo que una hipotética Democracia Directa sería y que la partícula "semi" parece querer indicar. No obstante, salvadas las diferencias de época, se podría afirmar que Democracia Semidirecta y Democracia Participativa son dos términos que hacen referencia al mismo concepto, si bien, con Democracia Participativa se hace referencia a una versión mucho más ampliada y centrado en lo local del mismo.

- Democracia Directa: es, o bien el modelo existente en la Atenas clásica, o bien un modelo utópico situado en un futuro hipotético y que, por lo general, suele implicar la utilización de sistemas informáticos y de las nuevas tecnologías de la información y la comunicación. No es en ningún caso nada que exista en el presente. Al ser directa implica necesariamente la inexistencia de fórmulas representativas, o la conversión de éstas en un mero instrumento para la racionalización y practicidad de la participación directa. Esto existía en Grecia en la antigüedad, tal vez exista en el futuro, pero es desde luego evidente que no existe en el presente. Existe la participación directa de los ciudadanos, pero no el todo que el concepto Democracia Directa implica.

- Participación Ciudadana: implica la participación directa de los ciudadanos en el gobierno de la comunidad y en la vida pública en general pero con un grado de intensidad menor que el de la Democracia Participativa $^{25}$, caracterizándose esencialmente porque el ciudadano puede recibir información de la administración, opinar ante ella, ser escuchado, ser tenido

${ }^{24}$ Decía Fraga que «la auténtica realidad de que los actuales partidos políticos propenden no sólo a actuar como intermediarios, sino a monopolizar el proceso político, necesita una compensación. Esa compensación, en democracias más antiguas que la nuestra (...) ha consistido en el desarrollo de instituciones democráticas semidirectas, entre las cuales está el referéndum, el plebiscito en materia internacional, la iniciativa popular, y una fórmula que aquí no hemos intentado, que tiene su importancia, que es el derecho de revocación por parte de los electores y elegidos.» Herrero Lera, M. citando el BOC número 109, de 13 de julio de 1978, pp. 4208-4209, en Alzaga Villaamil, Ó. «Comentarios a las Leyes Políticas. Constitución Española de 1978», tomo VII, Revista de Derecho Privado, Editoriales de Derecho Reunidas, Madrid, 1985, pp. 216-217.

${ }_{25}$ BRADY indica que la participación sería simplemente la «acción del ciudadano ordinario dirigida a influir en algunos resultados políticos.» AAVV. Ciudadanos, asociaciones y participación en España, Centro de Investigaciones Sociológicas, Madrid, 2006, pp. 48-49. 
en cuenta, pero no necesariamente tomar personalmente y de manera directa decisiones. La gran mayoría de actividades participativas del presente, particularmente en el ámbito local, encajan mucho mejor en la Participación Ciudadana que en la Democracia Participativa. Participación Ciudadana sería una esfera mayor que englobaría todas las actividades consideradas de participación directa del ciudadano y en cuyo interior encajaría una menor y más estricta caracterizada por la capacidad del ciudadano de decidir directamente y que sería la Democracia Participativa.

- Fenómeno Participativo: «término del que se ha servido en diversas ocasiones la jurisprudencia constitucional y que hace referencia a todas aquellas formas de participación que regula la Constitución a lo largo de su articulado, incluyendo entre ellas mandatos de carácter general dirigidos a los poderes constituidos para que promuevan la participación en determinados ámbitos (artículos 9.2 CE y $48 \mathrm{CE}$ ), el derecho a participar directamente en los asuntos públicos derivado del artículo 23.1 CE (artículo en el que se fundamenta en España la Democracia Participativa y la Participación Ciudadana) y también otros derechos subjetivos que, siendo de participación, no son de participación política como el recogido en el 23.1 CE.» ${ }^{26}$

\section{DEMOCRACIA PARTICIPATIVA Y DEMOCRACIA REPRESENTATIVA.}

La Democracia Participativa y la Democracia Representativa van necesariamente unidas. La Democracia Participativa surge del propio desarrollo de la Democracia Representativa y no pretende eliminarla o substituirla. Su objetivo es complementarla, enriquecerla y mejorarla. ${ }^{27}$ Pero nunca eliminarla. Si bien, una cierta visión utópica considera que tarde o temprano una renacida Democracia Directa substituirá a la Democracia Representativa sirviéndose para ello de las nuevas tecnologías, lo cierto es que, ni parece factible que vaya a resurgir un modelo de gobierno plenamente directo, ni parece posible que el sistema representativo se desmorone o siquiera evolucione tan drásticamente. ${ }^{28}$ Lo más lógico es concebir la Democracia Re-

${ }^{26}$ Ramírez Nárdiz, A. Guía práctica de la Democracia Participativa. Conocer la Democracia Participativa y aprender a usarla, Dykinson, Madrid, 2012, p. 111.

27 Indica Alzaga en este sentido que «partiendo pues de la idea de que el principio democrático ha de tener su plasmación principal en la Democracia Representativa, los mecanismos de participación directa se han contemplado en no pocas ocasiones como correctivos necesarios frente a las carencias de aquella y la oligarquización de los partidos, principales instrumentos del proceso representativo.» Alzaga ViLlaAmiL, Ó. Derecho político español según la Constitución de 1978, Edersa, Madrid, 1996, p. 294.

28 «En ese sentido, cabría decir que la democracia constitucional exige, por principio, la democracia representativa. Y así fue, en el Estado constitucional, hasta el presente, sin que hoy, pese a las modernas facilidades telemáticas (voto electrónico, etc.), hayan decaído aquellas razones (que son teóricas y no sólo prácticas). Lo que no impide, claro está, que como complemento de la democracia representativa, y no como su sustitución, quepa 
presentativa como un modelo político que, desde su mismo comienzo, se encuentra en constante desarrollo y evolución. Evolución que llevó en su día a ampliar el derecho de sufragio de los hombres con recursos a todos los hombres independientemente de su riqueza, a las mujeres, a las minorías raciales previamente discriminadas, etc. Evolución que en las últimas décadas se materializa en la Democracia Participativa y que busca que la ciudadanía participe más activamente ${ }^{29}$ en la vida pública y en la toma de decisiones entendiendo esto como un método de implicarla más activamente en dicha vida pública y, por extensión, como una herramienta para garantizar la continuidad de la Democracia como sistema político imperante y ampliar, a los ojos de los ciudadanos, la legitimidad del modelo democrático. ${ }^{30}$

La Democracia Participativa aparece precisamente en los años sesenta y setenta en el ambiente general de cambio y evolución que se produce en aquel tiempo y que en el ámbito político pretendía, entre otras cosas, reformular el modelo democrático existente acercándolo a los ciudadanos, a las minorías y a los grupos más desfavorecidos. Es por tanto, en el seno de la crisis (entendida como cambio y evolución) de la Democracia Representativa cuando surge la Democracia Participativa y es la, tan citada por la doctrina, crisis de la representación ${ }^{31}$ la que ha alimentado y aun hoy alimenta el desarrollo de la Democracia Participativa. ${ }^{32}$ No es, por tanto, posible concebir la Democracia Participativa sin la Democracia Representativa. Van

admitir determinados instrumentos de democracia directa (referéndums, especialmente) para la adopción de decisiones de muy especial trascendencia, o determinadas fórmulas de participación, que no de decisión, directa (por ejemplo, la iniciativa legislativa popular) en el Estado constitucional. Así se ha hecho en numerosos Estados constitucionales sin que por ello quiebre la democracia representativa, siempre que aquellos instrumentos o fórmulas se presenten como excepción y no como regla general, de suerte que no sirvan para deslegitimar a la representación política, que ha de considerarse, por lo antes dicho, como el sustento de la democracia constitucional.» ARAGón ReYes, M. op. cit., 2008, pp. 130-131.

${ }^{29}$ Hay que tener en cuenta, como apunta Manin, que «los fundadores del gobierno representativo no trataron de crear un sistema en el que gobernase la voluntad popular» si bien tampoco se puede negar que «no deseaban tampoco que las decisiones de los representantes no tuviesen relación con lo que desean los votantes.» MANIN, B. op. cit., Madrid, 1998.

${ }^{30}$ El Tribunal Constitucional en la STC 103/2008, de 11 de septiembre, FJ 2a , apuntó que la democracia española «se trata de una democracia representativa como regla general, complementada con determinados instrumentos de democracia directa, que han de operar, como es lógico y constitucionalmente exigido, no como minusvaloración o sustitución sino como reforzamiento de esa democracia representativa.»

31 «Parece que la brecha entre gobierno y sociedad, entre representantes y representados, se está ampliando.» Manin, B. op. cit., Madrid, 1998.

${ }^{32}$ Nuevamente son de obligada referencia aquí las reflexiones de Habermas. HaberMAS, J. Ensayos políticos, Ediciones península, Barcelona, 1988. 
e irán necesariamente unidas y como desarrollo de la segunda es como hay que entender a la primera.

\section{INSTRUMENTOS DE LA DEMOCRACIA PARTICIPATIVA.}

La Democracia Participativa se materializa en una serie de instrumentos o mecanismos jurídicos mediante los cuales se canaliza la participación directa de los ciudadanos. Estos instrumentos se dan en los distintos ámbitos de la administración (nacional, regional y local), si bien, dónde más se practican y dónde más instrumentos nuevos surgen es en el ámbito de lo local. Algunos de estos instrumentos jurídicos son:

a) Referéndum: es el instrumento participativo clásico. En términos generales consiste en una pregunta hecha a la ciudadanía sobre una cuestión política o reforma legislativa. A nivel doctrinal suele diferenciarse entre el referéndum propiamente dicho, que sería una pregunta sobre una reforma legislativa, y el plebiscito, que sería una pregunta sobre una cuestión política. De forma común, sin embargo, la diferenciación entre ambas palabras suele radicar en el carácter positivo de la palabra referéndum y el peyorativo (unido al ámbito de lo demagógico y populista) de la palabra plebiscito. También se puede diferenciar entre el referéndum y la consulta popular. En general, se consideran términos sinónimos, si bien en España se entiende (en particular desde la STC 103/2008, de 11 de septiembre, la cual sigue la línea jurisprudencial marcada por sentencias como la STC 119/1995, de 17 de julio, o la STC 12/2008, de 29 de enero) que el referéndum es aquel autorizado por el Estado, que sigue el procedimiento electoral, en el que es llamado a votar el cuerpo electoral y en el que se pregunta a dicho cuerpo electoral sobre los asuntos públicos y la consulta popular como aquella realizada sin que se den alguna o algunas de las características anteriores. En principio, el referéndum sería propio del ámbito nacional y la consulta popular de los ámbitos territoriales autonómico y local.

b) Iniciativa popular: con ella se eleva una petición popular a la autoridad política. La única ${ }^{33}$ existente en España es la iniciativa legislativa popular, que consiste en la recogida de un número determinado de firmas que se elevan a la autoridad legislativa competente solicitándole que legisle sobre un determinado asunto. La iniciativa popular, no obstante, puede promover otro tipo de peticiones más allá de la redacción de una ley: convocatoria de

33 Salvo en el ámbito local, donde, además de la iniciativa legislativa popular, existe la posibilidad de que las iniciativas populares locales lleven incorporada una propuesta de consulta popular local, la cual, en su caso, ha de ser tramitada siguiendo los requisitos y procedimiento contenidos en el artículo 71 de la Ley 7/1985. Consultas populares para cuya realización, así como para facilitar la participación y la comunicación con los vecinos, los municipios han de impulsar la utilización interactiva de las tecnologías de la información y la comunicación, tal como indica el punto tres del artículo 70 bis. 
un referéndum, revocación de una norma jurídica, remoción de un cargo político, etc.

c) Revocatoria de mandato: busca que una determinada autoridad o cargo político abandone su puesto o se someta a una nueva votación para mantenerlo. La ciudadanía recogerá las firmas que estipule la normativa jurídica y promoverá la solicitud. El cargo político afectado puede ser desde un alcalde hasta el presidente del país. Es un mecanismo relativamente popular en América pero de escasa aceptación en Europa.

d) Apelación de sentencia: por la misma se somete a votación popular una sentencia de un tribunal de justicia. Puede ser una sentencia que declare la inconstitucionalidad de una ley o una sentencia que habilite una situación jurídica inicialmente imposibilitada por una autoridad administrativa o por un tribunal inferior. En el referendum que se realice se podrá decidir mantener en el ordenamiento una ley declarada inconstitucional por el tribunal al tiempo que la sentencia será anulada. O se podrá anular una sentencia que declaraba conforme a Derecho una situación jurídica que en un primer momento no había sido permitida bien por una autoridad administrativa, bien por un tribunal inferior. Al igual que la revocatoria de mandato, es un instrumento participativo más habitual en América que en Europa.

e) Asamblea abierta: es «la reunión de la totalidad de los ciudadanos con derechos políticos de una comunidad sustituyendo así a las asambleas representativas. En la mayor parte de los casos, esta práctica se realiza a nivel local/municipal siendo las decisiones así tomadas del mismo ámbito competencial. Este sistema de adopción de decisiones políticas también puede denominarse -en Iberoamérica- cabildo abierto. En la actualidad el mecanismo de la asamblea abierta es, en muchos casos, una herramienta para llevar a cabo otros instrumentos de la democracia participativa tales como los presupuestos participativos, los núcleos de intervención participativa, etc. ${ }^{34}$

f) Presupuestos participativos: son el «instrumento de la democracia participativa -en principio local aunque también puede ser regional- mediante el cual el gobierno municipal consigna una determinada parte del presupuesto de un municipio - no suele ser la totalidad pero tampoco es imposible que lo sea- para su administración y utilización en aquellos objetivos que decida no el gobierno municipal unilateralmente, sino dicho gobierno municipal en colaboración con los vecinos del municipio, los cuales participarán en el proceso de decisión de los objetivos a alcanzar con esa parte del presupuesto municipal, así como en el modo de alcanzar dichos objetivos, ya sea simplemente siendo oidos en sus necesidades y deseos o, además de siendo oidos, decidiendo en qué y cómo se gasta. $\rangle^{35}$

\footnotetext{
34 Ramírez Nárdiz, A. op. cit., Valencia, 2010, pp. 186-187.

35 Ramírez NÁrdiz, A. op. cit., Valencia, 2010, p. 194.
} 
g) Jurados ciudadanos: también llamados núcleos de intervención participativa. En palabras de Dienel son «un grupo formado de personas elegidas al azar y liberadas de sus trabajos cotidianos por un tiempo limitado, de forma remunerada, para tratar de buscar soluciones a problemas preestablecidos, siendo asistidos por organizadores responsables. $\rangle^{36}$ Son, por tanto, un número de personas escogidas al azar (generalmente 25) y divididas en grupos de trabajo de 5 personas, que durante unos 3 a 5 días quedan liberadas de sus tareas cotidianas y a las que se les pide que, en el marco de unas jornadas de trabajo y siendo remuneradas por ello, participen en la discusión y resolución de alguno/s de los problemas de la localidad (o del barrio, la provincia, etc.) de la que forman parte siendo ayudados por moderadores, asesores técnicos expertos y en colaboración con las organizaciones y asociaciones de la localidad. ${ }^{37}$

\section{ESTADO DE LA DEMOCRACIA PARTICIPATIVA EN LOS DISTINTOS ÁM- BITOS TERRITORIALES: LA IMPORTANCIA DEL ÁMBITO LOCAL.}

Si la Democracia Participativa tiene futuro, éste será en el ámbito territorial local. ${ }^{38}$ Es en el ámbito local donde más se práctica, donde más se innova, donde aparecen nuevos instrumentos participativos, donde surgen más y más concejalías y departamentos de gobierno local dedicados a la participación ciudadana, donde resulta más sencillo el intercambio de información entre la administración y el ciudadano y donde, con menos esfuerzo, se pueden alcanzar cotas más elevadas de participación directa. La Democracia, al fin y al cabo, nació hace veinticinco siglos en una ciudad, así pues, no es tan extraño que, por paradójico que pueda resultar, si la participación directa del ciudadano en los asuntos públicos y en su gobierno ha de aparecer, crecer y desarrollarse, sea de nuevo en el ámbito de las ciudades. Adaptada, eso sí, a las circunstancias actuales, limitada a las competencias políticas que hoy en día tienen las ciudades y encuadrada en el marco general de Democracia Representativa imperante en el presente. La Democracia Directa no se pensó

36 Dienel, P.C. y Harms, H. op. cit., Barcelona, 2000, p. 83.

37 Ramírez NÁrdiz, A. op. cit., Valencia, 2010, p. 188-189.

38 Siguiendo a CANAles Aliende se pueden citar los motivos que parecen exigir una mayor participación ciudadana en el ámbito de lo local: la proximidad; la complementariedad de lo local con lo global; la diversidad, la complejidad y la pluralidad de redes políticas y sociales existentes en el nivel local; la preeminencia de lo urbano; la aparición de nuevos problemas y conflictos sociales y medioambientales; la lucha contra la inseguridad ciudadana; el debate público mayor y más intenso sobre el presupuesto local como instrumento de gobierno y de participación; la necesidad de fortalecimiento de la pertenencia e integración del ciudadano en una determinada comunidad humana y política; la generalización de la heterogeneidad social y territorial urbana; la aparición de grandes aglomeraciones urbanas; la accesibilidad de la ciudadanía a las instituciones y políticos locales; etc. Canales Aliende, J.M. «La democracia participativa local», Sistema, Revista de ciencias sociales, $\mathrm{n}^{\mathrm{o}}$ 184-185, 2005, pp. 191-201. 
para comunidades políticas mayores de unos pocos miles de personas, tal como era la Atenas de Pericles. Y lo cierto es que la Democracia Participativa existe y está regulada, junto con el local, en ámbitos territoriales de mayor tamaño pero, a más grande es el ámbito, más exiguo es el alcance de la participación directa de los ciudadanos, tanto en calidad, como en cantidad. A más aumenta el marco territorial, más disminuye el número de instrumentos participativos y las ocasiones en las que estos se practican.

Así, si se examina el desarrollo y estado internacional de la Democracia Participativa en la actualidad, es fácil comprobar cómo, tanto en el ámbito nacional, como en el ámbito regional, su desarrollo es limitado o muy limitado. Especialmente grave es la situación de la Democracia Participativa a nivel nacional en la mayoría de los países de nuestro entorno y, en particular, en España. Salvo muy contadas excepciones (determinados países iberoamericanos o Suiza) la Democracia Participativa en su ámbito nacional no tiene hoy gran predicamento. Uno de los casos en los que esta situación queda más patente es, precisamente, el caso de España. Para resumir la situación de la Democracia Participativa en su ámbito nacional en España baste decir que, de los tres instrumentos participativos nacionales que recoge la Constitución de $1978^{39}$, uno se ha practicado dos veces (referendos consultivo de la OTAN en 1986 y de la Constitución Europea en 2005) y los otros dos ninguna (pues nunca ha habido un referendo para la ratificación de la reforma constitucional y ninguna de las aproximadamente 60 iniciativas legislativas populares promovidas ha conseguido acabar convertida en una ley). ${ }^{40}$

${ }^{39}$ No se incluyen aquí los referendos para la elaboración y reforma de los Estatutos de Autonomía regulados por la Constitución (artículos 151-152 CE y disposición transitoria $4^{\mathrm{a}} \mathrm{CE}$ ) por ser su ámbito de realización el autonómico y no el nacional.

${ }^{40}$ La situación de la Democracia Participativa de ámbito nacional en España es fruto de una pluralidad de factores que van desde la restrictiva regulación Constitucional de la misma debida a la preocupación de los constituyentes porque una regulación demasiado amplia sacara de la sede parlamentaria a la calle el debate político en un momento tan delicado como era la Transición; la limitativa regulación legal de los instrumentos participativos nacionales (LO 2/1980, de 18 de enero, sobre la regulación de las distintas modalidades de referendo, y LO 3/1984, de 26 de marzo, reguladora de la iniciativa legislativa popular) que dificulta enormemente las posibilidades reales de participación y decisión del ciudadano; o los escasos estímulos políticos que tiene un responsable político español de ámbito nacional para promover la realización de un instrumento participativo (por ejemplo, un referendo consultivo), pues, siendo como es el debate político español, lo más probable es que dicho instrumento acabe convirtiéndose en un plebiscito sobre el propio responsable político y su gestión ignorándose el objeto real de dicho instrumento participativo y no suponiendo para el responsable político ningún beneficio real y muchos perjuicios potenciales tales como que la opción que él defiende en el instrumento participativo sea derrotada o no obtenga un apoyo manifiesto o provoque la división de su propio electorado, etc.

Toda esta suma de factores ha llevado a que en el presente la Democracia Participativa de ámbito nacional en España sea, en la práctica, un fósil que, si bien se encuentra 
A nivel nacional la Democracia Participativa se encuentra en un momento de estancamiento con tendencia al retroceso. Salvo contadas excepciones, como las novedosas experiencias participativas reguladas en algunas recientes constituciones iberoamericanas, la regulación y práctica de la Democracia Participativa de ámbito nacional en el conjunto de Occidente es cada vez más irrelevante. El número de referendos convocados, el número de iniciativas populares llevadas a cabo, etc. es escaso y de valor menor y, lo que es más importante, la dinámica no parece indicar que la situación vaya a cambiar a mejor, esto es, a un aumento de las experiencias participativas, sino a justo lo contrario, a peor, a su disminución. El tradicional miedo de los responsables políticos nacionales al recurso al voto ciudadano directo vive en el presente acrecentado y multiplicado. La crisis económica y su consecuencia política en forma de falta de credibilidad de la clase política y aumento del desapego y la desconexión entre la ciudadanía y sus políticos ha llevado a estos a no sólo no confiar en la Democracia Participativa como recurso para volver a conectar con la ciudadanía, sino a desconfiar ahora más que nunca de la participación directa por poderse erigir en altavoz de unos ciudadanos enfadados, hastiados y decepcionados con sus dirigentes.

Un ejemplo de este fenómeno se puede ver en el proceso por el que la Constitución Europea fue sometida en su día a diversos referendos ratificatorios a lo largo y ancho de la Unión Europea, no sucediendo así con su sucesor el Tratado de Lisboa. El desastre y desconcierto que supuso para la Unión Europea comprobar en sucesivos referendos nacionales que la ciudadanía estaba en contra de la Constitución Europea llevó a substituir la misma por un nuevo tratado de la UE que, por pura prudencia, no fue sometido a referendo con la misma alegría con la que había sido sometida la Constitución (sólo se sometió a referendo en Irlanda y, para zozobra de europeístas, ganó el "no". Afortunadamente para la UE, un año después Irlanda volvió a votar y en esta ocasión ganó el "sí"). La Democracia Participativa se convirtió en objeto a temer por la clase política que comprobó como la misma podía constituirse en un muy sólido obstáculo a sus propuestas y objetivos.

Si esto sucede a nivel nacional, a nivel regional la situación no es tan acentuada pero tampoco llamativamente mejor. Efectivamente, se comprueba la norma según la cual a más pequeño es el ámbito territorial, más desarrollo alcanza la Democracia Participativa. Esto implica que la Democracia Participativa regional está más desarrollada que la nacional pero menos que la local. Evidentemente, dependerá del país al que nos dirijamos y no será lo mismo el desarrollo suizo que el británico. Entre las propias regiones de un país tampoco acostumbra a haber un desarrollo homogéneo y suelen coexistir regiones con un desarrollo muy elevado con otras que no lo tienen

regulado tanto en la Constitución como en normas inferiores, no tenga un desarrollo ni una práctica sustantiva más allá de episodios puntuales que son más excepciones que confirman la regla que verdaderos logros participativos. 
en absoluto. En cualquier caso, en términos generales, el desarrollo participativo regional es superior al nacional y su progreso, si bien no comparable al local, es real. Ejemplos de esto lo encontramos en multitud de países europeos. Baste citar el ejemplo de Alemania, donde la Democracia Participativa de ámbito nacional brilla por su ausencia, mientras que la regional en los Länder o Estados Federados es mucho más fructífera. ${ }^{41}$ En España la Democracia Participativa de ámbito autonómico vive en el presente un periodo de interesante desarrollo y no poca polémica. La mayoría de las CCAA tienen legislación en materia de iniciativa legislativa popular y progresivamente son más las que regulan, o intentan regular, las consultas populares y la participación ciudadana en su conjunto. ${ }^{42}$

Pero donde realmente la Democracia Participativa se desarrolla y multiplica es en el ámbito local. Es aquí donde los responsables políticos parecen más propensos a promover una regulación amplia de los instrumentos participativos e, incluso en no pocos casos, a innovar y crear nuevos instrumentos participativos. El ejemplo español es paradigmático de la situación internacional de la Democracia Participativa: una regulación nacional detenida o en retroceso, una regulación regional que crece pero desigualmente entre las distintas regiones y una regulación local que aumenta a un ritmo que llega a hacer difícil conocerla en su totalidad. Cada vez son más los ayuntamientos que tienen una concejalía de participación ciudadana y que organizan actividades participativas que van desde el intercambio sencillo de información entre la administración y la ciudadanía, hasta la realización de instrumentos participativos complejos como presupuestos participativos o jurados ciudadanos a los cuales pueden dedicar una parte significativa del presupuesto municipal. El número de seminarios y congresos sobre Democracia Participativa se multiplica y parece que todos los ayuntamientos mínimamente cercanos al ciudadano deben tener el suyo al menos una vez al año. La cantidad de publicaciones promovidas por los municipios en las que se explican sus actividades participativas crece y su distribución se amplía. Incluso no son pocos los municipios que complementan los instrumentos participativos incorporando a ellos las nuevas tecnologías de la información y la comunicación y una consulta popular local la practican mediante voto electrónico o unos presupuestos participativos se desarrollan recogiendo las

${ }^{41}$ Por citar un ejemplo de esto quepa referirse al caso de los Estados Federados de Schleswig-Holstein, Baja Sajonia y Brandeburgo en los que se realizaron en 1998 tres consultas populares regionales: dos contra la reforma de la ortografía y una contra la construcción de un tramo del Transrapid -tren rápido de suspensión magnética- entre Hamburgo y Berlín. Jung, O. Democracia directa en Alemania. Tendencias desde 1989, Goethe Institut Inter Nationes, Bonn, 2001, pp. 1-18.

${ }^{42}$ Como la Comunidad Valenciana con la Ley 11/2008, de 3 de julio, de Participación Ciudadana. 
sugerencias ciudadanas a través de correos electrónicos dirigidos a la página web del ayuntamiento. ${ }^{43}$

La gran limitación de la Democracia Participativa local radica en la limitación de las competencias locales, así como en una financiación que no siempre acompaña a las administraciones que más cerca están del ciudadano y que suelen recibir más peticiones del mismo. Un ayuntamiento no puede ir más allá de sus competencias legales, sin embargo, cuando pone en práctica un instrumento participativo, la mayoría de los ciudadanos suele exigirle que vaya más allá de lo que por previsión legal y capacidad material puede ir. Este fenómeno se podría salvar con una coordinación entre las distintas administraciones (en España entre la local y la autonómica, particularmente), pero no siempre es sencillo y no siempre se lleva a cabo. No son pocas las ocasiones en que la Democracia Participativa y la Participación Ciudadana son vistas por la autoridad política más como una herramienta para conseguir réditos políticos, que como un instrumentos para mejorar el nivel democrático de una comunidad, así como para mejorar su nivel de vida. Esto, unido a una ciudadanía que muchas veces no conecta con los instrumentos participativos a los que ve (tanto, en ocasiones, por su propia falta de voluntad, como por la escasa capacidad de muchas administraciones de hacérselos ver más y mejor) lejanos, complejos y poco útiles, lleva a multitud de disfuncionalidades en la práctica participativa (populismos, escasa participación ciudadana real, falta de continuidad en la práctica participativa, etc.). En este marco, no es de extrañar que muchas administraciones locales tiendan a actuar en solitario o con interconexiones muy limitadas con las restantes administraciones.

El ámbito de lo local es, por tanto, el que parece mostrarse cada vez más claramente por cantidad y calidad como el característico de la Democra-

${ }^{43}$ Ejemplo muy interesante de esto último se puede ver en los presupuestos participativos de San Juan de Alicante en los que se permitía que los ciudadanos presentaran sus quejas y solicitudes mediante el envío de correos electrónicos a la página web del ayuntamiento. Quepa citar algunas peticiones ciudadanas recogidas en la web del ayuntamiento para los presupuestos participativos del año 2008 (www.santjoandalacant.es):

-Número de registro 003-08: «Conciliación de la vida laboral y familiar. Creo que es una obligación de las Administraciones Públicas crear guarderías públicas. Ahora que he sido madre recientemente, me doy cuenta de la importancia que tienen las cosas para facilitar a las madres dicha conciliación. Creo que URGE en San Juan una guardería/ escuela infantil YA.»

-Número de registro 066-08: «Propongo la creación de un huerto en el patio del colegio público Cristo de la Paz. Constaría de una serie de pilones rectangulares, como de 1,20 $\mathrm{m}$ de altura, rellenos de tierra donde se plantarían las hortalizas y demás plantas.»

-Número de registro 154-08: «Alergias. Los chopos sueltan pelusas blancas y cuando hay viento parece que nieva. Los alérgicos lo pasamos fatal. Cortar chopos (Dr. Pérez Mateo) residencia médicos.» 
cia Participativa, pero, precisamente por ello, en él se reúnen los progresos, avances y mejores en el campo participativo, pero también gran parte de las limitaciones, miserias y frustraciones que el mismo presenta en la actualidad. El elemento clave es, sin duda, el ciudadano ${ }^{44}$. Es de él de quien, en definitiva, depende la Democracia Participativa.

\section{CONCLUSIONES.}

Como indicó BerLin, «puede que sin el empuje de las fuerzas sociales las ideas nazcan muertas. Pero de lo que no hay duda es de que, si no se revisten de ideas, esas fuerzas quedarán cegadas y faltas de dirección. ${ }^{45}$ El desastre al que está abocado cualquier movimiento social que carezca de un mínimo trasfondo ideológico queda meridianamente claro cuando se examina el desarrollo en los últimos años de movimientos sociales españo-

${ }^{44}$ En las presentes páginas se han utilizado en diversas ocasiones los términos ciudadano y ciudadanía, pero no el de pueblo. Esto es así debido a la desconfianza que el propio concepto pueblo genera. El ciudadano o la ciudadanía es un concepto eminentemente empírico, es decir, resulta posible observar a los ciudadanos individualmente o como colectivo, esto es, como agregación de individuos que componen el todo llamado ciudadanía; e igualmente posible es predicar derechos individuales de los ciudadanos. Pero el pueblo, como concepto mucho más indeterminado - más metafísico que jurídico-, abierto a interpretaciones que incluyan, o no, a todos los habitantes de un determinado territorio en función de sus condiciones comunes no necesaria y estrictamente jurídicas (raza, ideología, religión, etc.), del que, en no pocas ocasiones, se han predicado y aun hoy se predican supuestos derechos previos al Estado y, por ello, superiores al ordenamiento determinado por el mismo y al que se tiende a apelar para intentar transformaciones sociales que no pocas veces lesionan los derechos individuales de los ciudadanos, es un concepto al que resulta problemático acudir en ámbitos jurídicos tales como, por ejemplo, el que es objeto de estas líneas: la Democracia Participativa. Quepa citar a FERnÁndEZ-Miranda CAMPOAMOR cuando indica « Hay que ser muy cuidadoso cuando se habla de pueblo y de voluntad del pueblo. Pese a que ya nos hemos referido a ello en otro momento, conviene repetirlo ahora e, incluso, ampliarlo, a efectos pedagógicos. Veamos. Es evidente que el pueblo, como realidad sociológica con capacidad de expresar una voluntad política coherente y operativa, ni existe ni puede existir. El pueblo, como realidad sociológica, es un complejo agregado de individuos que se integran o se organizan a través de una multiplicidad de estructuras heterogéneas, frecuentemente enfrentadas y contradictorias. Sociológicamente no hay una voluntad del pueblo que preexista al Estado y reclame hacerse presente en él. El pueblo, como realidad homogénea, con capacidad de un querer unitario y coherente: O es un concepto metafísico, así, por ejemplo, la "voluntad general" de Rousseau, que es una noción que está más allá de la voluntad de los individuos y que ni siquiera se corresponde con la voluntad de la mayoría. O es un concepto jurídico: es decir, una realidad fabricada por y desde el derecho.» FERnández-Miranda CAMPOAMOR, A. «Reflexiones sobre una improbable reforma del sistema electoral del Congreso de los Diputados», Revista de Derecho Político, no 74, UNED, enero-abril 2009, pp. 40-41.

${ }_{45}$ Berlin, I. Dos conceptos de libertad y otros escritos, Alianza, Madrid, 2010, pp. 45-46. 
les como el 15-M o el 25-S. Estos movimientos de protesta carecen de una verdadera ideología, de unos objetivos concretos y determinados, así como de un programa y liderazgo visibles. Están destinados, por tanto, al fracaso ${ }^{46}$. Pero idéntico destino le aguarda a aquellas ideas que no tengan suficiente apoyo de las fuerzas sociales. Y, para ser apoyada, una idea ha de ser primero mínimamente conocida. La Democracia Participativa es joven. En muchos aspectos prácticamente nueva $\mathrm{y}$, por ello, muy desconocida. Siguiendo con el ejemplo de los movimientos de protesta $15 \mathrm{M}$ o $25 \mathrm{~S}$, ¿podrían los manifestantes de la Puerta del Sol haberse servido de la Democracia Participativa? Sí, si la hubieran conocido. Podían haberla utilizado para racionalizar y sistematizar las asambleas populares que se practicaron. $\mathrm{O}$ para recoger firmas y plantear iniciativas legislativas populares. Pero la desconocían. O la confundían con modelos utópicos y ajenos a la realidad. He ahí el gran reto que los instrumentos participativos tienen en el presente: superar su desconocimiento por los ciudadanos. El verdadero problema que la Democracia Participativa tiene en el presente para desarrollarse no son tanto los poderes públicos que recelan de ella, sino los ciudadanos que la desconocen.

Igualmente, y como se ha indicado anteriormente, la Democracia Participativa es y será lo que el ciudadano quiera que sea. Sus instrumentos requieren de la participación del ciudadano. Ciudadano que, además, ha de tener una mínima formación, ya sea previa o adquirida con la práctica del instrumento participativo. Si bien en la Democracia Representativa el papel del ciudadano puede limitarse al ejercicio de su derecho al voto o, incluso, puede ser inexistente si éste decide no votar, en la Democracia Participativa es imprescindible que el ciudadano se implique y tome parte en los instrumentos participativos. La Democracia Representativa puede sobrevivir con tasas de participación bajas. La Democracia Participativa, cuya esencia es precisamente la participación del ciudadano, no tiene futuro si el ciudadano se abstiene de participar. El modelo participativo es propio de sociedades formadas y responsables, con altos valores cívicos y con la conciencia de que sólo mediante la cooperación y el consenso se produce el progreso social. Es propio, por tanto, de sociedades maduras y con un alto estándar democrático. A través de la Democracia Participativa se puede formar al ciu-

${ }^{46}$ La crítica a la Democracia Participativa tiende, sin embargo, a identificarla con este tipo de movimientos sociales y a acusarla de sacar la representación del parlamento a la calle y, con ello, de debilitar el sistema democrático. Nada más lejos de la realidad, pues la función de la Democracia Participativa es, precisamente, el fortalecimiento del sistema democrático y el enriquecimiento de la Democracia Representativa. No es rupturista, ni revolucionaria, sino que, por el contrario, es moderada y busca el fortalecimiento de las estructuras democráticas acercándolas al ciudadano y sometiéndolas a un mayor control del mismo. 
dadano ${ }^{47}$, pero difícilmente se podrá practicar la misma si el ciudadano no es ya y con carácter previo un sujeto formado y democráticamente responsable.

De la necesidad de que se den simultáneamente este conjunto de factores (conocimiento de qué es la Democracia Participativa, participación elevada de los ciudadanos en los instrumentos participativos, formación y responsabilidad de los sujetos participantes, etc.) deriva la complejidad del establecimiento a largo plazo de modelos propios de la Democracia Participativa. Estos altos requisitos explican igualmente por qué en el presente los instrumentos participativos, en términos generales y a salvo del ámbito local, se utilizan de forma esporádica y aislada y, en no pocas ocasiones, por motivaciones populistas, pervirtiendo así su verdadera naturaleza y reduciéndolos a parodia de sí mismos. La Democracia Participativa es joven, desconocida y dista mucho de estar asentada. Puede y está llamada a ser un importante elemento de desarrollo de la Democracia Representativa y del conjunto del sistema democrático. Pero su pervivencia y propia consolidación no está, ni mucho menos, garantizada. Dependerá de la voluntad de los distintos legisladores y gobernantes, pero, sobre todo, dependerá de la voluntad de los ciudadanos, sus verdaderos protagonistas.

TITLE: The challenges of democracy: participative democracy as complement of representative democracy.

Resumen: La Democracia Participativa es una de las áreas de la teoría y práctica jurídica y política que con más fuerza se desarrolla en los últimos años. En el presente comprobamos que el recurso a la apelación a la ciudadanía no sólo no decrece, sino que, particularmente en determinados ámbitos territoriales, aparece con intensidad como opción o solución que dé legitimidad a las decisiones procedentes de unas instituciones representativas que sufren un periodo de intensa crítica social. Conocer el origen histórico y doctrinal de la Democracia Participativa, distinguirla de otros conceptos cercanos, entender los instrumentos de los que se compone y calcular en que ámbitos tiene unas mayores posibilidades de desarrollo futuro resulta, ahora más que nunca, de especial importancia.

${ }^{47}$ Los presupuestos participativos son buen ejemplo de esto, pues allí donde se han practicado (partiendo de Porto Alegre en 1989 y continuando con ejemplos tan dispares como los que se han dado en Europa o en Asia) han requerido que el ciudadano participante adquiriese formación no sólo sobre el propio funcionamiento del presupuesto participativo, sino también sobre las obras a realizar en el municipio, los materiales a usar, los gastos a efectuar, etc. Es decir, los ciudadanos que participan en unos presupuestos participativos no sólo adquieren conocimientos jurídicos o políticos, sino también económicos o, incluso, técnicos propios de la construcción, dándose la circunstancia (particularmente en los casos en los que se han realizado presupuestos participativos en ámbitos con grandes niveles de analfabetismo) de que, para poder participar en los presupuestos participativos, era condición necesaria y previa formarse adecuadamente. 
PaLABRAS ClaVE: Derecho, Democracia Participativa, Democracia Representativa, Participación Ciudadana, instrumento participativo.

ABstract: Participative Democracy is one of the areas of the legal and political theory and practice that in the last years is being developed in a stronger way. Nowadays we check that the appeal to the citizenship is not decreasing but, particularly in some territorial scopes, appears with intensity as option or solution to give legitimacy to the decisions coming from representative institutions that are suffering a period of intense social critic. To know the historical and doctrinal origin of the Participative Democracy, to distinguish it from other close concepts, to understand the tools of which it is formed and to calculate in which areas it has bigger future development possibilities is, now more than never, of special relevance.

KEY WoRDS: Law, Participative Democracy, Representative Democracy, Citizenship Participation, participative tool.

Recibido: 05.07.2012 Aceptado: 18.01.2013 